\title{
KOMUNIKASI MODEL LASWELL DAN STIMULUS-ORGANISM- RESPONSE DALAM MEWUJUDKAN PEMBELAJARAN MENYENANGKAN
}

\author{
Dani Kurniawan \\ Mahasiswa S2 Ilmu Komunikasi, Universitas Sebelas Maret \\ Email : denihoki@gmail.com
}

\begin{abstract}
Abstrak.
Penelitian ini dilakukan atas dasar permasalahan dalam komunikasi pendidikan. Objek penelitian ini adalah Taman Pendidikan Al-Quran (TPA) Melda. Penelitian ini bertujuan untuk mengetahui pola komunikasi yang diterapkan oleh institusi pendidikan Alquran yaitu : TPA. Apakah komunikasi yang dijalankan masih apa adanya atau sudah direncanakan dan dirancang secara sistematis. Metode yang digunakan dalam penelitian ini adalah kualitatif. Teori yang digunakan adalah model komunikasi Laswell dan S-O-R (Stimulus, Organism, Response). Hasil penelitian ini menunjukkan bahwa komunikasi memiliki peran penting bagi kemajuan pendidikan. Buktinya bisa dilihat pada model komunikasi yang diterapkan di TPA Melda. Komunikasi pembelajaran yang diterapkan oleh TPA Melda telah dirancang secara sistematis sehingga anak-anak mengalami pembelajaran yang menyenangkan. Hasil lainnya adalah aspek kognitif dan aspek afektif dalam pembelajaran di TPA ini tercapai.
\end{abstract}

Kata kunci : model komunikasi, pembelajaran menyenangkan

\section{LASWELL COMMUNICATION MODEL AND STIMULUS- ORGANISM-RESPONSE FOR CREATNG FUN LEARNING}

\author{
Dani Kurniawan \\ Master Student of Communication Studies in Sebelas Maret University \\ Email:denihoki@gmail.com
}

\begin{abstract}
This research is conducted on the 1 basis of the problem communication education. The object of this research is the Taman Pemdidikan Al-Quran (TPA) Melda. This research aims to determine the communication patterns applied by educational institution for Quran, especially TPA. It is whether the communication is still running as it is or has been planned and designed sistematically. The method used in this research is qualitative. The theory of communication model by Laswell and S-O-R (Stimulus, Organism, Response) are used as well. The result of this study shows that communication has an important role for the progress of education. The evidence can be seen in the communication model applied in the TPA Melda.The learning communication applied by TPA Melda has been systematically designed so that children experienced fun learning. As a result, cognitive aspect and affective aspect in learning are achieved in this TPA.
\end{abstract}

Keywords : communication model, fun learning. 


\section{PENDAHULUAN}

Komunikasi mempunyai peran penting dalam segala aspek kehidupan, termasuk dunia pendidikan. Proses pendidikan tidak bisa dilepaskan dari aktivitas komunikasi karena komunikasi berperan sebagai tools (perangkat) dalam proses transfer keilmuan dari seorang komunikator (pendidik, pengajara, guru) kepada komunikan (anak didik). Oleh karena itu, agar transfer pengetahuan (materi pelajaran) dapat berjalan dengan baik maka seorang pendidik harus memiliki skill (kemampuan/keahlian) komunikasi yang baik.

Sebaliknya jika seorang pengajar tidak mempunyai keahlian komunikasi dalam mengajar maka materi pelajaran tidak tersampaikan dengan maksimal kepada siswa/santri. Kemudian hubungan antara guru dan anak didik tidak terjalin secara harmonis. Alhasil yang dirugikan di sini adalah para siswa/santri dan dunia pendidikan itu sendiri.

Oleh karena itu skill communication (kemampuan komunikasi) harus dimiliki bagi setiap individu khususnya pendidik, guru. Menurut survei yang dilakukan National Association of Colleges and Employers (NACE) di Amerika Serikat tahun 2002 berdasarkan hasil jajak pendapat kepada 457 pengusaha, menyatakan skill komunikasi menjadi kebutuhan utama dunia kerja (dunia industri, bisnis, pendidikan) . Sehingga bagi lulusan perguruan tinggi kompetensi pertama kali yang harus dimiliki adalah skill komunikasi bukan Indek Prestasi Kumulatif (IPK) yang tinggi. Menurut survei NACE IPK justru berada di urutan No 17. Adapun indeks hasil penelitian berikut ini :

\begin{tabular}{lll}
\hline No & Kualitas & Skor \\
\hline 1 & Kemampuan & 4,69 \\
& Berkomunikasi & \\
2 & Kejujuran/integiritas & 4,59 \\
3 & Kemampuan bekerjasama & 4,54 \\
4 & Kemampuan interpersonal & 4,5 \\
5 & Etos kerjas yang baik & 4,46 \\
6 & Memiliki & 4,42 \\
7 & motivasi/berinisiatif & 4,41 \\
8 & Mampu Adabtasi & 4,36 \\
9 & Kemampuan analitikal & 4,21 \\
10 & Kemampuan computer & 4,05 \\
11 & Kemapuan beroganisasi & 4 \\
12 & Berorientasi pada detail & 3,97 \\
13 & Kemampuan memimpin & 3,5 \\
14 & Percaya diri & 3.85 \\
15 & Berkepribadian ramah & 3.82 \\
16 & Sopan/beretika & 3,75 \\
17 & Bijaksana & 3,68 \\
18 & IP 3.0 & 3,59 \\
19 & Kreatif & 3,25 \\
20 & Humoris & 3,23 \\
& Kemampuan & \\
& entrpreneurship & \\
& &
\end{tabular}

Sumber : Putra, Ikhsan S., dan Aryanti Pratiwi. Sukses dengan Soft Skill. Bandung : ITB. 2005

Berdasarkan data hasil survei di atas maka mempunyai keahlian komunikasi merupakan suatu kewajiban. Anda tidak boleh mengabaikan dan menyepelekan perkara ini. Untuk menjadi orang yang komunikatif caranya bisa dengan belajar dan berlatih. Semakin banyak belajar dan 
berlatih maka skill komunikasi terus asah dan kemampuan meningkat.

Dalam konteks pendidikan, komunikasi sebagai komponen utama menyampaikan materi pelajaran dari seorang guru kepada anak didik. Oleh sebab itu guru sebagai pengajar harus memiliki kemahiran komunikasi terutama komunikasi lisan dalam konteks instruksional. Kemahiran guru dalam berkomunikasi lisan dan instruksional itu akan menentukan keberhasilan siswa belajar (Suparno, 1999)

Namun seiring perkambangan zaman dengan kompleksitas masalah pendidikan, untuk menjadi pengajar yang komunikatif juga harus mengetahui aspek lain. Diantarnya harus mengetahui skema dan model komunikasi yang tepat untuk diterapkan dalam Kegiatan Belajar Mengajar (KBM). Skema komunikasi itu menjelaskan bagaimana komunikasi dalam bekerja.

Sedangkan model komunikasi lebih pada pendekatan yang tepat digunakan dalam komunikasi. Dua hal tersebut patut diperhatikan dan diperhatikan dalam komunikasi pendidikan. Karena tujuan komunikasi dalam pendidikan tidak hanya bisa mentransfer keilmuan kepada anak didik (kognitif) dan bagaimana mampu merubah sikap, perilaku anak didik (affective).

Sebelum terlalu jauh membahas dua hal di atas ada baiknya diketahui terlebih dahulu tentang pengertian komunikasi menurut para ahli. Menurut Hovland, Janis dan Kelly komunikasi adalah suatu proses melalui mana seseorang (komunikator) menyampaikan stimulus (biasanya dalam bentuk kata-kata) dengan tujuan mengubah, membentuk perilaku orang lain (komunikan/khalayak) (Sendjaja,2005:10).

Sedangkan komunikasi menurut Onong Uchjana Efendy adalah penyampaian suatu pernyataan oleh seseorang kepada orang lain (Efendy, 2005).

Kembali lagi untuk membahas hal tentang bagaimana memahami komunikasi dalam bekerja, sebenarnya banyak modelnya. Salah satu model yang cukup terkenal adalah model Lasswell. Karena model ini sederhana dan mudah dimengerti. Menurut Lasswell komunikasi akan berjalan dengan baik apabila melalui lima tahap. Kelima tahap itu adalah : Who : Siapa orang yang menyampaikan komunikasi (komunikator). Say What : Apa pesan yang disampaikan. In Which Channel : Saluran atau media apa yang digunakan untuk menyampaikan pesan komunikasi. To Whom : Siapa penerima pesan kominkasi (komunikan). Whit what Effect : Perubahan apa yang terjadi ketika komunikan menerima pesan komunikasi yang telah tersampaikan. Apabila digambarkan skema komunikasi model Lasswell berkerja dapat lihat sebagai berikut ini : 


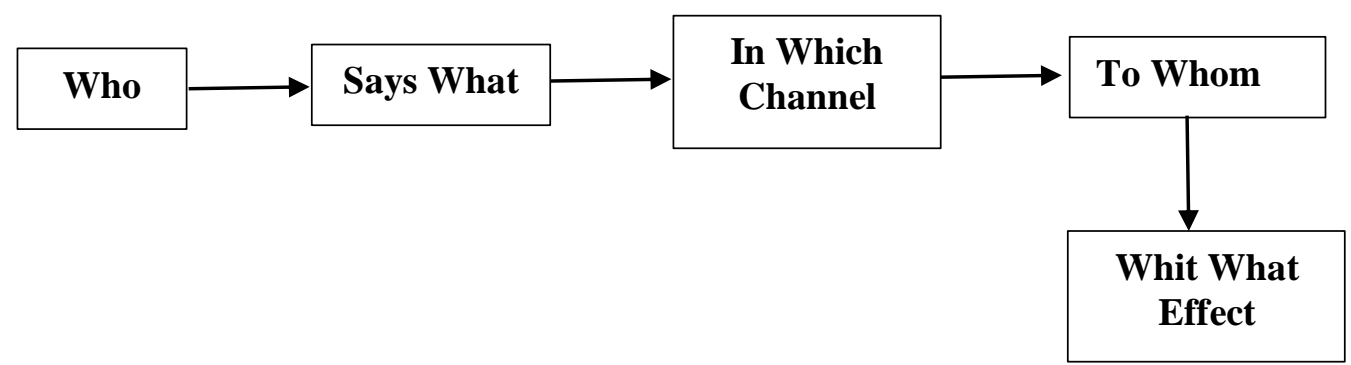

\section{Model Lasswell}

Sumber : Werner J. Severin and James W. Tankard, Jr. Communication Theories, Orgins, Methods and Uses in the Mass Media. New York : Logman, 1992, hlm. 38.

Gambar di atas memberikan penjelasan bagaimana komunikasi dapat bekerja secara sistematis sehingga hasilnya tepat sasaran. Lima unsur itu merupakan elemen pokok komunikasi yang tidak boleh ditinggalkan dalam melakukan komunikasi dengan siapa saja termasuk berkomunikasi dalam mengajar di kelas.

Walaupun demikian komunikasi jenis Lasswell itu masih kurang maksimal apabila diterapkan dalam komunikasi pendidikan. Supaya komunikasi pendidikan bisa berjalan dengan efektif harus ada penajaman maupun penekanan. Karena tujuan dari komunikasi pendidikan tidak hanya sebatas anak didik bisa menerima dan memahami materi yang disampaikan. Tetapi mampu merubah perilaku anak didik.

Oleh karena itu supaya komunikasi pendidikan dapat berjalan efektif maka komunikasi jenis Lasswell dikolaborasikan dengan model komunikasi yang lain. Model komunikasi yang tepat adalah jenis S-O-R (Stimulus-Organism-Respon). Teori S-O-R ditemukan oleh Hovland (1953) yang awalnya berasal dari psikologi. Namun dalam perkembangan juga digunakan dalam ilmu komunikasi.

Menurut teori stimulus response ini, dalam proses komunikasi, berkenaan dengan perubahan sikap adalah aspek “ how" bukan "what" dan "why”. Jelasnya how to communicate dalam hal ini how to change the attitude, bagaimana mengubah sikap komunikan. Dalam proses perubahan sikap, tampak bahwa sikap dapat berubah, hanya jika stimulus yang menerpa benarbenar melebihi semula. Dalam menelaah sikap yang baru ada tiga variabel yang penting yaitu perhatian, pengertian, penerimaan (Effendy, 2003 :254-255)

Titik penekanan dalam model komunikasi ini lebih kepada pesan yang disampaikan mampu menumbuhkan motivasi, menumbuhkan gairah kepada komunikan sehingga komunikan cepat menerima pesan yang diterima dan selanjutnya terjadi perubahan sikap perilaku. Onong Uchjana Efendy 
(2003.253) menjelaskan unsur penting dalam model komunikasi S-O-R itu ada tiga yaitu : Pesan ( Stimulus, S), Komunikan (Organims, O) dan Efek (Response, R). Apabila digambarkan skema komunikasi model S-O-R adalah sebagai berikut ini :

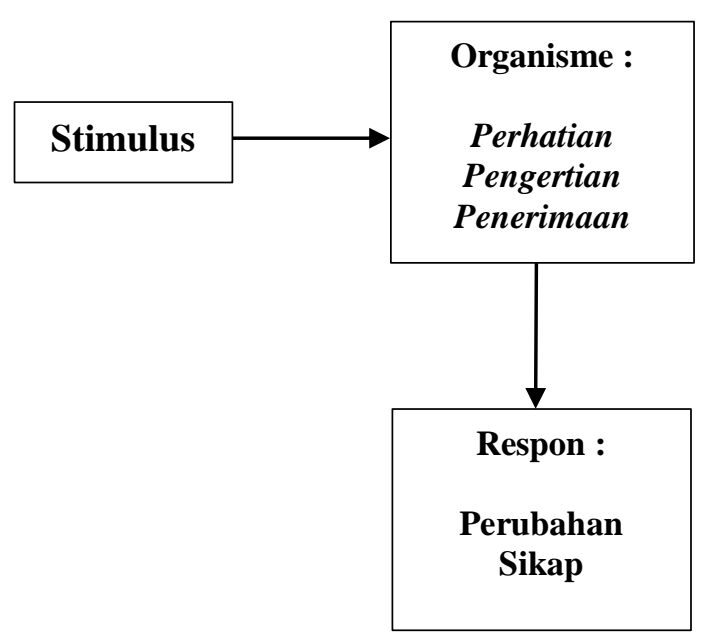

Sumber : Onong Uchjana Efendy . Ilmu,

Teori dan Filsafat Komunikasi, Bandung :

Citra Aditya Bakti. 2003, hal 253.

Berdasarkan gambaran di atas menunjukan alur bagaimana model komunikasi dilakukan dalam perubahan sikap. Pendek kata setiap aksi pasti ada reaksi begitu juga dalam komunikasi. Kemudian hal-hal yang patut diperhatian agar terjadi perubahan sikap maka stimulus yang disampaikan harus memenuhi tiga unsur yaitu perhatian, pengertian dan penerimaan.

Oleh karena itu, sebagai pendidik sebelum menyampaikan panjang lebar tentang materi pelajaran ada baiknya membuka pembicaraan dengan memberikan perhatian dan pengertian kepada anak didik.
Hal ini akan membuat mereka merasa nyaman sehingga mudah menerima materi dan mematuhi perintah apa yang disampaikan oleh guru.

Selain itu yang tidak boleh dilupakan, bahwa aktivitas komunikasi itu hanya sebatas molonolog (bicara satu arah) tetapi juga dialog (bicara dua arah). Komunikasi dua arah adalah kunci keberhasilan dalam pemberlajaran. Oleh karena, itu seorang guru dituntut untuk mengembangkan kemampuan berkomunikasi sekaligus memiliki kemampuan mendengar dan keterbukaan yang baik terhadap murid (Iova, 2013).

Mendengar juga merupakan komponen dasar dari proses komunikasi, selain berbicara, membaca dan menulis. Pendengar yang baik adalah mendengarkan secara aktif dengan menerima pesan secara akurat. Selain aktif mendengar juga harus interaktif dengan berinteraksi langsung lawan bicara dengan cara mengajukan pertanyaan dan memberikan penjelasan, pemaparan (Brezuleani, 2011)

\section{METODE PENELITIAN}

Penelitian ini menggunakan metode kualitatif dengan pendekatan diskriptif. Maksud dari metode kualitatif ialah sebagai prosedur penelitian yang menghasilkan data diskirptif berupa katakata yang tertulis atau lisan dari orangorang dan perilaku yang dapat di amati (Bogdan-Taylor, 1975 : 5). 
Tujuan dari penelitian deskriptif kualitatif ini adalah untuk mendeskripsikan apa-apa yang saat ini berlaku. Di dalamnya terdapat upaya mendeskripsikan, mencatat, analisis dan menginterpretasikan kondisi yang sekarang ini terjadi atau ada. Dengan kata lain penelitian deskriptif kualitatif ini bertujuan untuk memperoleh informasi informasi mengenai keadaan yang ada (Mardalis, 1999 :26)

Data yang digunakan dalam penelitian ada dua sumber yaitu : data primer dan data sekunder. Data primer adalah data utama dalam penelitian yang diperoleh langsung dari lapangan. Data primer diperoleh melalui observasi dan wawancara. Adapun yang dimaksud dengan observasi adalah : teknik pengumpulan data untuk mengamati prilaku manusia, proses kerja, dan gejalagejala alam, dan responden (Sugiyono, 2012 : 166).

Sedangkan definisi wawancara adalah percakapan dengan maksud tertentu. Percakapan itu dilakukan oleh dua pihak yaitu pewawancara (interviewer) yang mengajukan pertanyaan dan terwawancara (interviewee) yang memberikan jawaban atas pertanyaan itu (Meleong, 2016 : 1986).

Data yang kedua ialah data sekunder yaitu data yang diperoleh tidak langsung dari lapangan atau objek penelitian. Data sekunder dalam riset ini diperoleh dari dokumentasi. Dokumentasi adalah metode mengkaji dan mengolah data dari dokumendokumen yang sudah ada sebelumnya dan mendukung data penelitian. Dokumentasi adalah metode yang digunakan untuk menelusuri historis (Burhan, 2008 : 122).

\section{HASIL DAN PEMBAHASAN}

Hasil riset yang kami lakukan di Taman Pendidikan Al-Qur'an Melda secara umum menunjukan pola komunikasi memiliki pengaruh yang besar bagi anak didik. Oleh karena itu model komunikasi yang diterapkan dalam proses belajarmengajar di TPA Melda selama ini telah didesain, dirancang sebaik mungkin. Menurut Direktur TPA Melda Khoirudin, model komunikasi yang diterapkan yaitu menggunakan model Lasswell dan SOR (Stimulus-Organism-Response).

Dua model di atas selama ini berhasil mampu menghasilkan pembelajaran yang menyenangkan bagi anak didik (learning is fun). Dengan pembelajaran yang menyenangkan maka pendidikan di TPA Melati Muda menurut Ketua Bidang Pembelajaran Faris Naufal Ali itu telah berhasil. Hal itu bisa diukur paling tidak dari segi dua hal :

Aspek Kognitif: Nilai ujian anak didik baik. Anak-anak didik bisa membaca dan menulis Al-Qur'an sesuai waktu yang ditargetkan TPA Melda. Anak-anak didik cepat menghafal bacaan surat-surat pendek dalam Al-Qur'an Jus 30. Anak didik berani bertanya ketika apabila ada yang kurang faham materi yang disampaikan oleh pengajar 
Aspek Affective: Anak didik sudah melakukan sholat lima waktu. Anak didik sudah mulai menjalankan akhlaq kepada orang tua (menghormati orang tua). Anak didik telah menjalankan akhlaq yang baik kepada saudara dan sahabat dalam kehidupan sehari-hari. Anak didik telah menjalankan adab makan-minum dalam kesehariannya.. Tingkat kehadiran yang tinggi dari anak didik di atas $85 \%$ dari total jumlah anak didik sekitar 25 anak.

Indikator di atas menunjukan hasil bahwa dua model komunikasi Lasswell dan SOR yang diterapkan di TPA Melda telah sukses dalam mendidik anak didik dari aspek kognitif (pengetahuan) dan aspek affective (sikap).

Sejak awal pendirian Taman Pendidikan Al-Qur'an (TPA) Melda telah memperhatikan masalah komunikasi dalam proses ngajar-mengajar di kelas. Di sini telah ada rambu-rambu komunikasi yang disepakati. Adapun Rambu-rambu ini sangat berarti bagi pendidikan anak. Adapun rambu-rambu tersebut sebagai berikut ini :

Jika anak-anak dibesarkan dengan celaan, ia belajar memaki.

Jika anak-anak dibesarkan dengan permusuhan, ia belajar berkelahi.

Jika anak-anak dibesarkan dengan cemooh, ia belajar rendah diri.

Jika anak-anak dibesarkan dengan hinaan, ia belajar menyesali.
Jika anak-anak dibesarkan dengan toleransi, ia belajar menahan diri.

Jika anak-anak dibesarkan dengan dorongan, ia beljar percaya diri.

Jika anak-anak dibesarkan dengan pujian, ia belajar menghargai.

Jika anak-anak dibesarkan sebaik-baik perlakuan, ia belajar keadilan.

Jika anak-anak dibesarkan dengan kasih sayang, ia belajar menemukan cinta dalam hidupnya ( Jalalludin Rahmad,1992).

Secara sederhana intisari pesan di atas adalah pendidik di TPA Melda dalam berkomunikasi kepada peserta didik tidak boleh menggunakan bahasa yang negatif (celaan, cemooh, hinaan). Pengajar maupun pendidik dalam berkomunikasi harus menggunakan bahasa yang positif ( support, rasa kasih sayang). Bahasa merupakan salah satu bentuk pesan dan pesan itu adalah stimulus yang berpengaruh bagi komunikan (peserta didik). Jika stimulusnya positif maka perkembangan anak didik akan baik, begitu juga sebaliknya.

Berdasarkan observasi di lapangan saat proses belajar-mengajar di kelas TPA Melati menurut pengamatan penulis para pendidik dalam berkomunkasi telah melakukan dengan tepat, sesuai dengan apa yang digariskan oleh Lasswell. Untuk melihat prosesnya dapat dilihat sebagai berikut ini :

Pertama, Who : Siapa orang yang menyampaikan komunikasi (guru, pendidik, 
pengajar dan ustadz). Kedua, Say What : Apa pesan yang disampaikan. Dalam penyampaian pesan disinilah fungsi model SOR digunakan, peran SOR sebagai guidance (petunjuk) merancang sebuah pesan. Sesuai rumus SOR untuk membuat pesan yang baik itu harus ada tiga unsur (mengandung perhatian, mengandung pengertian dan penerimaan).

Dijelaskan pula setiap pesan itu stimulus memilik pengaruh kepada komunikan. Oleh sebab itu pesan komunikasi (verbal non verbal) yang disampaikan oleh pengajar, pendidik TPA Melda pertama kali kepada anak didik itu harus mengandung perhatian dan pengertian supaya timbul penerimaan. Apabila sudah ada penerimaan di hati dan pikiran anak didik maka pesan mudah diterima mereka.

Contoh pesan yang wajib disampaikan kepada anak didik adalah : memberikan senyuman, berjabat tangan, memberikan sapa, menanyakan kabar, mengelus kepada, mendoakan.

Setelah itu semua baru menyampaikan materi ajar seperti baca-tulis Al-Qur'an, menghafal surat-surat pendek, belajar gerakan sholat dan doa sholat, belajar dan praktek akhlaqul karimah dll

Selain itu agar suasana kelas menyenangkan, murid tidak ramai dan lebih fokus, biasanya setiap awal pertemuan dan diakhir pertemuan dilaksanakan ice breaking (tepuk tangan, bernyanyi, permainan memberikan reward). Ketiga, In
Which Channel: Saluran atau media pembelajaran apa yang digunakan untuk menyampaikan pesan komunikasi (White Board, LCD, Film, Buku, Video, Poster, Komik, Musik, Demontrasi).

Keempat, To Whom : Siapa penerima pesan komunikasi ( anak didik, siswa, santri). Kelima, Whit what Effect : Perubahan apa yang terjadi ketika komunikan menerima pesan komunikasi yang telah tersampaikan. Perubahan yang terjadi baik dari aspek kognitif dan affective anak didik dengan penerapan model komunikasi Lasswell dan S-O-R. Contohnya mereka bisa membaca dan menulis Al-Qur'an, hafal surat-surat pendek, bisa melaksanakan gerakan sholat dan doa sholat secara benar, memiliki akhlaq yang baik (adab kepada orang tua, kepada sahabat, adab makan dan minum).

Uraian di atas membahas tentang bagaimana model komunikasi Lasswell dan SOR telah berhasil dikolaborasikan secara sistematis diterapkan dalam proses pembelajaran di Taman Pendidikan AlQur'an (TPA) Melda.

\section{KESIMPULAN DAN SARAN}

Berdasarkan ulasan dan hasil penelitian ini maka dapat disimpulkan beberapa hal. Komunikasi mempunyai peran penting bagi keberhasilan sebuah pendidikan. Oleh karena itu komunikasi dalam pendidikan tidak boleh dijalan secara sembarangan. Komunikasi pendidikan 
harus direncanakan, dirancang, didesain secara sistematis supaya tujuan pendidikan dari aspek kognitif, affective dan motorik dapat tercapai.

Untuk merancang dan mendesain komunikasi dalam dunia pendidikan itu banyak pilihan. Namun pilihan model komunikasi yang tepat adalah model komunikasi jenis Lasswell dan S-O-R. Karena Model Laswell memberikan guidance (petunjuk) alur tahapan komunikasi yang tepat. Sedangkan model S-O-R memberikan guidance (petunjuk) tentang merancang pesan komunikasi agar mampu merubah sikap komunikan.

Meskipun demikian dunia pendidikan terus berkembang sehingga menghadapi permasalahan dan tantangan baru. Oleh sebab itu penerapan model komunikasi tidak boleh berhenti hanya dalam model Laswell dan S-O-R. Namun harus diterapkan dan dikembangkan model komunikasi yang lain supaya bisa menjawab permasalahan dan tantangan yang ada.

\section{DAFTAR PUSTAKA}

Andrei Radu IOVA. (2013). Aspect of The Communication in The Educational System. Case Study, High School Sector. Scientific Papers Series Management, Economic Engineering in Agriculture and Rural Development Vol. 13, Issue 2, p195-198.

Carmen Olguţa Brezuleanui, Stejărel Brezuleanui, Gabriela Ignat. (2011). Study Abouth Importance Of Effective Listening in Communication of Educational Managemen. Lucrari Stiinntifice, Vol. 54, Issue.2, p344-347

Bogdan dan Taylor, 1975 dalam J. Moleong, Lexy. (1989).Metodologi Penelitian Kualitatif. Bandung: Remadja Karya

Bungin, M. Burhan. (2008_. Penelitian Kualitatif. Jakarta: Kencana Prenada Media Group

Effendy, O. U. (2003). Ilmu Komunikasi Teor idan Praktek. Cetakan kesembilan belas. Bandung: PT Remaja Rosdakarya.

Effendy, O.U. (2004). Dinamika Komunikasi. Bandung : PT. Remaja Rosdakarya.

Lexy J. Moleong. (2016). Metodelogi Penelitian Kualitatif. Bandung : Rosda Karya.

Mardalis .(1999). Metode Penelitian Suatu Pendekatan Proposal. Jakarta : Bumi Aksara

Sasa Djuarsa Sendjaja. (2005). Pengantar Komunikasi. Jakarta: Universitas Terbuka.

Sugiyono. (2012). Metode Penelitian Kuantitatif Kualitatif dan $R \& B$. Bandung: Alfabeta

Suparno. (1999). Kemahiran BerKomunikasi Lisan dalam Konteks Instruksional Guru Sekolah Dasar. Jurnal Ilmu Pendidikan, Vol 6, No 1, hal 51-60

Rahmad, Jalaluddin. (1992). Islam Aktual. Bandung : Mizan 